\title{
Sociological explanation and mixed methods: the example of the Titanic
}

\author{
Jörg Stolz ${ }^{1}$ (D) Anaïd Lindemann ${ }^{1}$. Jean-Philippe Antonietti ${ }^{2}$
}

Published online: 24 December 2018

(c) The Author(s) 2018

\begin{abstract}
The question of how and with what methods the social sciences should explain phenomena is fiercely contested. While several scholars have argued that mixed methods may help to improve sociological explanations, there is a lack of highly visible examples that show the added value of this methodology. The goal of this paper is to show that the case of the Titanic, and the question of who survived and for what reasons, can be seen as such an example. The Titanic tragedy is the most well-known maritime disaster of modern history, and the Titanic dataset is a widely used and first-rate example for the teaching of mono-method statistical explanation. We demonstrate that a mixed-method explanation is superior to a mono-method explanation in that it clarifies not only the relationships between variables, but also the mechanisms that led to the co-variations. Among the most important mechanisms, we find that the rule "women and children first" was interpreted differently by different actors, and that this, together with the fact that different classes of passengers had different levels of access to the boat deck, explains much of the gender/ class differences in terms of survival that we can observe. We conclude by discussing the lessons that can be drawn from the example for sociological explanatory work more generally.
\end{abstract}

Keywords Sociological explanation $\cdot$ Mixed methods $\cdot$ Social games $\cdot$ Titanic

Jörg Stolz

joerg.stolz@unil.ch

Anaïd Lindemann

anaid.lindemann@unil.ch

Jean-Philippe Antonietti

Jean-philippe.antonietti@unil.ch

1 ISSR, University of Lausanne, 1015 Lausanne, Switzerland

2 Institute of Psychology, University of Lausanne, 1015 Lausanne, Switzerland 


\section{Introduction ${ }^{1}$}

The question of how and with what methods the social sciences should explain phenomena is fiercely contested, with various approaches and methodologies claiming superiority over their rivals (Gross 2009; Little 2012; Manzo 2010). While several scholars have shown that mixed methods may help to improve sociological explanations (Howe 2012; Ivankova et al. 2006; Kelle 2001; Lieberman 2005), there is a lack of highly visible examples with freely available datasets that demonstrate the added value of this methodology (Bryman 2008). ${ }^{2}$

The goal of this paper is to show that the case of the Titanic, and the question of who survived and for what reasons, can be seen as such an example. The Titanic tragedy is the most well-known maritime disaster of modern history, and its survival statistics are spectacular. For example, $96.5 \%$ of first-class female passengers survived compared to only $15 \%$ of third-class male passengers, and only $1.5 \%$ of the restaurant crew. For these reasons, the Titanic dataset has become a first-rate and widely used example for teaching mono-method statistical explanation. It is used to teach crosstabs, log-linear modeling, logistic regression, and goodness-of-fit, with SPSS, Stata, SAS, and R (Bellocco and Algeri 2013; Harrell 2001; Kohler and Kreuter 2017; Landau and Everitt 2004).

We demonstrate here that a mixed-method explanation is superior to a mono-method explanation in that it clarifies not only the relationships between variables, but also the mechanisms that led to the co-variations.

To do so, we integrate a qualitative content analysis of survival testimonies (our qualitative dataset with $\mathrm{N}=214$ ) and a survival analysis with data on attributes and survival of all passengers and crew (our quantitative dataset with $\mathrm{N}=2207$ ).

Former substantive analyses of the Titanic case are given by Hall (1986), Gleicher and Stevans (2004), and Frey et al. (2011). With respect to their findings, our paper shows some points that are already well known, such as the massive gender- and class differences. But our paper also adds several new substantive insights that we will detail in the conclusion. The most salient feature of our explanation is that the rule "women and children first" was interpreted differently by different officers, and that their lifeboat-filling practices, together with the fact that different classes arrived on average at different times on the boat deck, contributed greatly to the differences in survival between gender/class groups. By showing the exact mechanisms involved in the lifeboat-filling process, this explanation stands in stark contrast to the mono-method accounts that have been given in the literature (Frey et al. 2011; Harrell 2001; Kohler and Kreuter 2017; Landau and Everitt 2004).

The plan of the paper is straightforward. We review the literature on sociological, statistical, and mixed-method explanations (part 2), discuss our quantitative and qualitative data (part 3), describe the method (part 4), and present the results of the integrated survival and content analysis (part 5). We discuss the lessons to be drawn for sociological explanatory work more generally in part 6.

\footnotetext{
1 We thank two anonymous reviewers for helpful comments on a former version of this text.

2 We are in the process of constructing a website where the mixed-method datasets and context information on the Titanic example will be freely available.
} 


\section{Statistical explanation, sociological explanation, and explanatory mixed methods}

\subsection{Statistical explanations}

The question of who perished on the Titanic is treated in the mono-method literature by trying to "explain" or "predict" the binary variable "perished/survived" with the help of a number of explanatory variables such as gender, class/crew, age, and nationality (Frey et al. 2011; Gleicher and Stevans 2004; Hall 1986). While there is nothing to be said against teaching statistical methods with interesting datasets, well-known scholars from very different theoretical strands have long argued that proper explanation in the social sciences involves more than the fit of statistical models.

Such scholars criticize statistical explanations for their failure to see that it is actors, not variables, who "do the acting" (Esser 1996), for neglecting the institutional and cultural framing of the situation (Blumer 1998/1969), and for not giving enough attention to time and process (Abbott 2001). We do not want to discuss the appropriateness of these criticisms abstractly here, but only note that, when it comes to scholarly writing on the Titanic case, they do seem to be justified in almost all cases. Most of the statistical explanations based on the Titanic dataset do indeed make variables do the acting, neglect the institutional, cultural, and spatial context, and fail to model the process of events. For example, everyone even mildly acquainted with the Titanic case knows that the crew, and especially the officers, had a very important role to play in the process of saving lives. But as actors they normally do not show up in the scholarly accounts-because there are no corresponding variables on them in the quantitative datasets. We do not want to debunk the statistical or substantive literature on the Titanic, and the authors cited present state-of-the-art publications. Our point is rather that the state of the art can be improved by applying mixed methods (Stolz 2016).

\subsection{Sociological explanations}

It is strongly debated in the sociological literature just what form "good" sociological explanations should take. We do not have space to describe the different meta-theories that are used for such explanations, the most important of which are probably rational choice and methodological individualism (Boudon 2001; Coleman 1990), analytical sociology (Hedström 2005; Manzo 2010), social-practice theory (Bourdieu 1980), and pragmatist approaches (Gross 2009). Whatever the exact formulation they use, all of these forms of explanation claim that actors interact in some sort of structure (system, mechanism, ensemble of rules), thereby creating the outcome.

In this paper, we use a social games perspective, which means that providing a sociological explanation involves describing a causal relationship that is transmitted through a social game. A social game is an interaction between players (with their attributes) that involves goals, rules, resources, and representations, in a temporal and spatial context (Klabbers 2003; Stachura 2017; Swedberg 2001). The methodology linked to the theory of social games may be called "game heuristics" and invites us to search empirically for the most important features of the social game played by the actors in a given situation and then to explain by showing how a change in a game parameter (i.e. a rule change, a change in resources) has causally led, through the playing of the game, to a change in the 
output. Alternatively, we can show how game parameters that differently apply to different types of players (i.e. a rule that treats men and women differently) causally lead, through the playing of the game, to different outputs. We employ the theory of social games and game heuristics because we think that it is particularly suited to mixed-method explanations. Social games have elements (e.g. rules) that are evidently meaning-based and have to be "understood" qualitatively. But they also have inputs and outputs (e.g. player attributes, game scores) that can be counted, measured, and explained quantitatively. Also, the elements of social games can be conceptualized, observed, and measured in a straightforward way. Note, though, that our main focus in this paper is not the presentation of this metatheory of social games. ${ }^{3}$ Rather, our main argument is independent of the specific metatheory used.

\subsection{Explanatory mixed methods}

A growing number of researchers in the social sciences are using mixed methods; that is, they combine quantitative and qualitative methods and data (Bergman 2008; Johnson and Onwuegbuzie 2004; Lieberman 2005). We wish to sidestep general discussions about the "nature" of "qualitative" and "quantitative" data, research, or epistemologies. For our purposes, it suffices to recognize that different data types typically come with different strengths and weaknesses, and that combining these data types may therefore increase the validity of descriptions and explanations (Johnson and Turner 2003).

In our specific example, the advantage of using mixed methods for explanatory purposes lies in the fact that the quantitative dataset of all passengers and crew allows us to measure and correlate inputs and outputs of the "social game" in the form of explanatory variables such as "class/crew", "gender", and the outcome variable "time when a person boards a lifeboat". The qualitative dataset consists of a large number of survivor testimonies that recount just what happened in the "social game" from the perspective of the survivor, permitting us to extract the typical game-elements and game-mechanisms at work. Combining the analyses of these two datasets, we can (1) better specify and interpret our quantitative model, and (2) better interpret the qualitative evidence, and put it into perspective. In this way, an explanation results that not only predicts different survival rates for different groups, but also shows why these different rates came about.

\section{The sinking of the Titanic and hypotheses concerning survival statistics}

\subsection{The sinking of the Titanic}

As is well known, the Titanic hit an iceberg on 14 April 1912 at 11:40 pm and it sank completely about two hours and 40 min later at about 2:20 am (Eaton and Haas 2011;

\footnotetext{
3 We do not have space to go more into detail concerning the theory of social games and the methodology of game heuristics. In a companion paper we will present more in detail the use of game heuristics when analyzing the Titanic case. A future paper will also give an outline of the theory of social games. Note that the theory of social games should not be confounded with (economic) game theory (von Neumann and Morgenstern 2004/1944). The theory of social games uses none of the central elements of economic game theory, such as strict rationality assumptions, pay-off matrices, or the concept of equilibrium.
} 


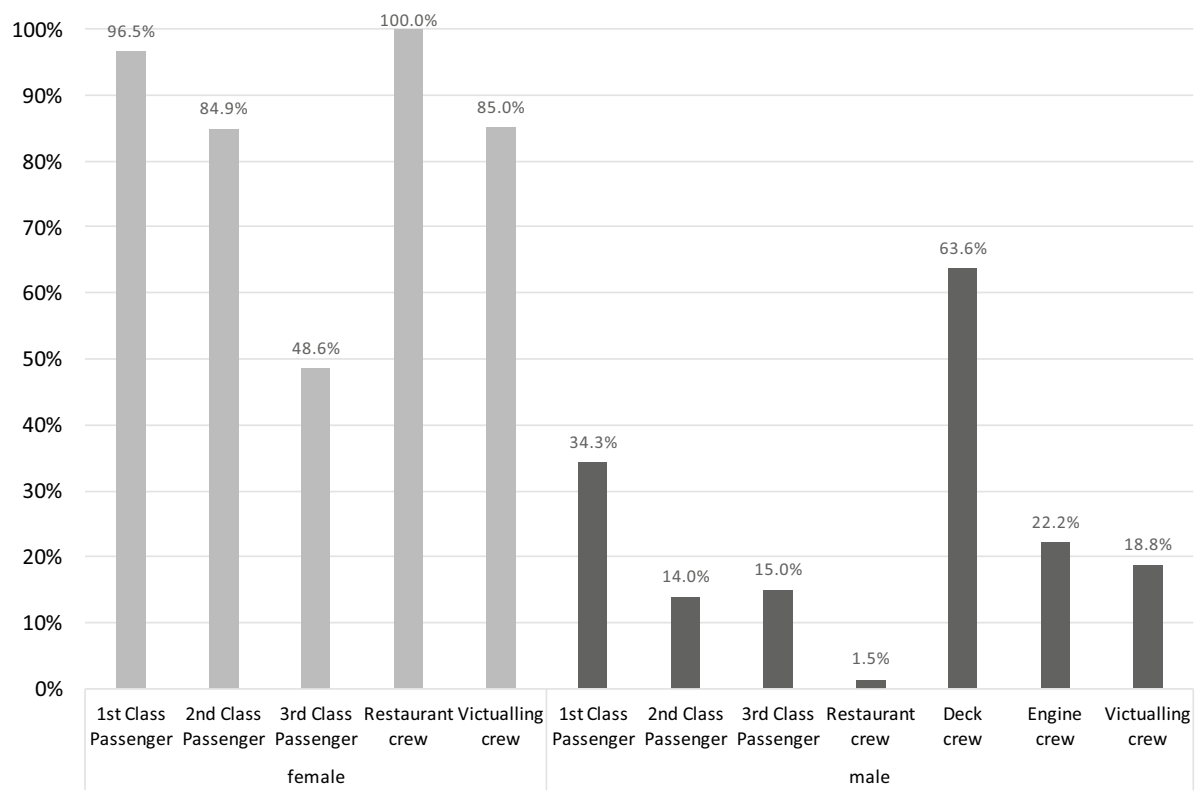

Fig. 1 Survival on the Titanic according to gender, class, and type of crew

Lord et al. 2012/1956). The survival statistics show strong co-variations between gender, class, and survival, and have fascinated both laypeople and scholars ever since. In Fig. 1, we show not only the percentage differences between different classes, but also the very important differences between different types of crew-a point that is almost always overlooked in the literature. We can sum up the findings as follows:

- Women across all classes and types of crew generally have a higher survival probability than men (e.g. first-class female passengers, $96.5 \%$ vs. first-class male passengers, $34.4 \%$ ). The one exception is that male deck crew have a higher survival probability with third-class female passengers.

- Higher-class passengers generally survive more often than lower-class passengers (e.g. first-class female passengers, $96.5 \%$ vs. second-class female passengers, $84.9 \%$, vs. third-class female passengers, $48.6 \%$ ). The one exception is that there is no significant difference between second-class and third-class male passengers.

- We find interactions between gender and class. There is a large difference between firstclass and second-class female passengers who survive (more than 80\%) and third-class female passengers who survive (only $48.6 \%$ ); for men, the major difference is between first-class male passengers who survive (34.4\%) and second-class and third-class male passengers, who have very similar survival rates of $14 \%$ and $15 \%$ respectively.

- The men belonging to the restaurant crew have the lowest survival rate of all groups of men with only $1.5 \%$ (both women belonging to the restaurant crew survive).

- Male deck crew have the highest survival probability of all the groups of men (63.6\%).

The intriguing question is of course: how can these differences and interactions be explained sociologically? 


\section{Hypotheses}

The literature on the Titanic and sociological theory would suggest a number of hypotheses, which we can briefly enumerate here:

H1 Gender. The higher survival probability of women might be explained by the rule governing the filling of lifeboats, "Women and children first". This rule could be effective either as an individual rule or as a rule enforced and sanctioned by officers and crew.

H2 Class. The higher survival probability among the higher classes might be explained by discrimination (a) when filling the lifeboats, (b) when informing the different classes of what was happening, or (c) concerning access to the boat deck. In all these cases, discrimination could be either manifest or latent/structural. For example, access to the boat deck for lower classes might be restricted on purpose, or it might be the case that access was simply more difficult on account of the boat's spatial architecture.

H3 Age. Children should have a higher survival probability because of the rule "women and children first", and younger adults might have more chance to survive than older adults because of their greater physical strength.

H4 Nationality. Non-English-speaking nationalities might have lower survival probabilities because they were less able to understand instructions given by the crew. In contrast, however, Frey et al. (2011) found that individuals of English nationality had lower survival probabilities on the Titanic than other nationalities, speculating that this might be because they were too polite.

H5 Social ties. Individuals who are traveling with others might have a higher survival probability because their network might give them a better chance of being informed and helped. Furthermore, individuals with children might receive privileged access to a lifeboat.

\section{Data and method}

Our analytical strategy is to combine a survival analysis of the time when individuals boarded lifeboats with a content analysis of survivors' accounts of the fatal night, to tease out the game-mechanisms that led to the differences in survival probabilities. We use a convergent mixed methods design, with the goal of combining qualitative and quantitative data in a concurrent timing and with equal priority to profit from non-overlapping weaknesses and strengths of the different methods (Creswell and Plano Clark 2010). Such a design calls for a strong integration of the datasets at the level of individuals and concepts.

\subsection{Quantitative dataset and variables}

Our quantitative dataset $(\mathrm{n}=2207)$ was created from the Encyclopedia Titanica and crosschecked by various other sources in Frey et al. (2011). ${ }^{4}$

${ }^{4}$ We thank David A. Savage for letting us use these data. 
We use time of boarding a lifeboat and survival (yes/no) as our central dependent variables. It was (almost) impossible to survive the Titanic incident without boarding a lifeboat at one point or another.

Since we can reconstruct the time that each lifeboat left the Titanic, and since it is known (in most cases) which passengers were taken into a lifeboat from the Titanic, and which from the water, we can estimate the points in time when the survivors entered the lifeboats. In practical terms, we assigned to every surviving individual the time when his or her lifeboat left the Titanic. Individuals who could not board a lifeboat were assigned the time of the last lifeboat. In practice, some individuals were transferred between lifeboats, and some (very few) people were picked up from the water. We took care to assign the times of boarding the lifeboat on the Titanic and assigned the censoring time to people picked up from the water. There is some uncertainty for some individuals in terms of the lifeboat that they actually boarded-but the possible bias is in our view rather small since the time of boarding is normally rather similar when it comes to the possible lifeboats that a specific individual could have boarded. The independent variables are:

- Gender (male, female).

- Age is a continuous variable and has been analyzed in this form in many of our models. For greater simplicity, we use two dummies in the models presented: one for age $<15$ (a child as defined on the Titanic), and one for being 51 and older. The reference category comprises all other ages.

- Class and type of crew are distinguished in one variable with attributes "1st class", "2nd class", "3rd class" for passengers, and "restaurant crew", "deck crew", "engine crew", and "victualling crew" as different types of crew. Officers are coded as "deck crew". We introduced this variable into the survival analysis with dummies, the victualling crew being the reference category.

- Country of residence was recoded as two dummies representing "English" and "American". Other nationalities are the reference category.

- Social ties were measured by two dichotomous variables: "single/not single", and "with children/without children".

- Side of boat is a dichotomous variable that distinguishes individuals that entered boats on the port side (on the left) and on the starboard side (on the right). This variable is not used in the regression analysis since it strongly correlates with the filling of lifeboats in different phases.

\subsection{Survival analysis}

Conceptualizing our dependent variables as time of boarding a lifeboat and yes/no survival allows us to use survival analysis to capture the element of time in the survival of different individuals. Previous research could not do this, because it employed the dichotomous variable survived/perished as its dependent variable. We used the survivalpackage in R (Fox and Weisberg 2011; Thomas and Reyes 2014). Note that, since we have data on all individuals on the Titanic, there is no sampling error and therefore no need for descriptive inference. However, we can think of statistical inference as concerning the data-generating process and thus use it for causal inference (Kohler and Kreuter 2017, p. 255). 
Table 1 Passengers and crew, survivors, and testifiers

\begin{tabular}{|c|c|c|c|c|c|c|}
\hline & \multicolumn{2}{|c|}{ Testifiers } & \multicolumn{2}{|c|}{ Survivors } & \multicolumn{2}{|c|}{$\begin{array}{l}\text { Passengers } \\
\text { and crew }\end{array}$} \\
\hline & $\mathrm{N}$ & $\%$ & $\mathrm{~N}$ & $\%$ & $\mathrm{~N}$ & $\%$ \\
\hline Women & 93 & 43.2 & 351 & 49.9 & 485 & 22.0 \\
\hline Men & 121 & 56.8 & 353 & 50.1 & 1722 & 78.0 \\
\hline 1. Class & 69 & 32.1 & 200 & 28.4 & 324 & 14.7 \\
\hline 2. Class & 34 & 15.8 & 115 & 16.3 & 285 & 12.9 \\
\hline 3. Class & 36 & 16.7 & 178 & 25.3 & 708 & 32.1 \\
\hline Restaurant crew & 2 & 0.9 & 3 & 0.4 & 69 & 3.1 \\
\hline Deck crew & 28 & 13.0 & 42 & 6.0 & 66 & 3.0 \\
\hline Engine crew & 17 & 7.9 & 72 & 10.2 & 325 & 14.7 \\
\hline Victualling crew & 29 & 13.5 & 94 & 13.4 & 430 & 19.5 \\
\hline English & 122 & 57.0 & 293 & $41.6 \%$ & 1164 & 52.7 \\
\hline US-American & 58 & 27.1 & 207 & $29.4 \%$ & 424 & 19.2 \\
\hline Other & 34 & 15.9 & 204 & $29.0 \%$ & 619 & 28.0 \\
\hline $\mathrm{N}$ & 214 & $100 \%$ & 704 & $100 \%$ & 2207 & $100 \%$ \\
\hline
\end{tabular}

\subsection{Qualitative dataset and validity issues}

A second dataset contains the testimonies of 214 survivors. These testimonies have been taken from the Encyclopedia Titanica ${ }^{5}$ and the British and American trial proceedings. ${ }^{6}$ The survivor testimonies were grouped according to the lifeboat that enabled the individual to survive. These testimonies come in a variety of forms: (a) interviews given to journalists; (b) testimonies given at the trial proceedings; (c) journalists' accounts of what survivors had told them; (d) letters to family or friends; (e) affidavits. They were given at very different times, in different contexts, to a different public, and are of very different lengths (the shortest contains a few sentences, the longest more than 280 pages).

A note on the validity of these testimonies: evidently, various biases are possible. A first bias is produced by the (obvious) fact that we have testimonies only of surviving individuals, who are not a random subset of individuals. Second, only a subset of survivors provided a testimony, and the selection is certainly not random, with precedence being given to men, individuals of high status, and people of an Anglo-Saxon heritage. This is a form of "sampling on the dependent variable", where the selection has been effectuated by the natural and social process itself. It is well known in quantitative research that "sampling on the dependent variable" is problematic, since it may lead in its extreme form to a complete lack of variance in the dependent variable or, in its mild form, to biased (underestimated) regression coefficients (King et al. 1994, p. 129).

Besides the selection, other biases may also result from the fact that individuals (a) may have poor recollection of the events, and all the more so since these events were clearly extremely traumatic; (b) may confuse their memories with stories that they have since heard or films that they have since watched; (c) may adapt their stories to their audience in order to create specific effects, for example embellish their role or render certain points

\footnotetext{
5 https://www.encyclopedia-titanica.org.

${ }^{6}$ http://www.titanicinquiry.org/about.php.
} 
more dramatic; (d) may withhold or invent important information, especially if they fear negative judgment of their behavior.

While there is no doubt that there are various possibilities of bias, we can also counter them in powerful ways; this is precisely the advantage of using mixed methods:

(1) Since our qualitative dataset is nested in the quantitative dataset, we can inspect the size of selection bias concerning gender, class/crew, and nationality in Table 1.

(2) As survivor testimonies are qualitative accounts that all refer to the same event, they contain valuable information about what happened not only to those testifying, but also to others (both surviving and non-surviving), and about the evolving context as a whole. By triangulating different testimonies, we can often make very precise assertions about what happened on the boat deck, and build quite a good (albeit less reliable) picture of the routes to the boat deck that different classes took.

(3) Again, because the qualitative and quantitative datasets are all concerned with the same social game, we may also triangulate and cross-check results between data types.

\subsection{Qualitative content analysis and coding scheme}

Our qualitative content analysis is inspired by techniques suggested by Mayring (2014) and was conducted with MAXQDA. Starting with our research question, we developed a coding scheme inductively that consists of 29 codes, grouped under our five hypotheses. Once the coding scheme was stable, all the material was systematically recoded according to this scheme. All codes have an explicit coding rule. ${ }^{7}$ Many codes are given in a double version; that is, where a certain event or action is experienced or done by survivors themselves or is observed with regard to other individuals. This allows us to quantify our qualitative data and count, for example, how many survivors in our qualitative dataset from different classes experienced difficulties when trying to reach the boat deck (Teddlie and Tashakkori 2009, p. 269f).

\subsection{Linking the datasets}

The two datasets are linked in two major ways. First, at the level of the individuals concerning individual names as well as all our dependent and independent variables. The quantitative dataset includes all 2207 passengers on the Titanic. The qualitative dataset includes a subset of the surviving individuals who have given a testimony. This allows us, for example, to select and compare what third-class male passengers who survived tell us about their survival as compared to, say, first-class male passengers who survived. We compare the samples in Table 1. For gender and class, our dataset represents the survivor characteristics quite well: men, first-class passengers, and deck crew are slightly overrepresented, while women, third-class passengers and engine crew are slightly underrepresented. Nevertheless, we have an important number of survivors in all relevant groups who testified, except the restaurant crew (which is explained by their very low survival rate). We also linked the datasets through the concepts measured in both datasets. This was done by specifying the different possible

\footnotetext{
7 Two coders coded the material. We checked the consistency of our coding procedures by calculating inter-coder agreement for all survivors in boat 1 for three central codes and arrived at a concordance of at least $80 \%$ for all documents checked.
} 
Table 2 Cox proportional-hazards regression on the time that survivors boarded lifeboats (survival analysis)

\begin{tabular}{|c|c|c|c|c|c|}
\hline & $\begin{array}{l}\text { Model } 1 \\
\text { Coef }\end{array}$ & $\begin{array}{l}\text { Model } 2 \\
\text { Coef }\end{array}$ & $\begin{array}{l}\text { Model } 3 \\
\text { Coef }\end{array}$ & $\begin{array}{l}\text { Model } 4 \\
\text { Coef }\end{array}$ & $\begin{array}{l}\text { Model } 5 \\
\text { Coef }\end{array}$ \\
\hline Gender & $1.740 * * *$ & $1.865 * * *$ & $1.806 * * *$ & $2.519 * * *$ & $2.76^{* * *} *$ \\
\hline Child & -0.041 & $.355 *$ & $.363^{*}$ & $0.797 * * *$ & .050 \\
\hline 1. Class & & $.763 * * *$ & $.724 * * *$ & $.851 * * *$ & -.083 \\
\hline 2. Class & & .070 & .033 & -.333 & -.295 \\
\hline 3. Class & & $-.727 * * *$ & $-.836^{* * *}$ & $-.391 *$ & $-.458 * *$ \\
\hline Restaurant crew & & $-1.638^{* *}$ & $-1.637 * *$ & $-1.573 * *$ & $-1.559 * *$ \\
\hline Deck crew & & $1.626 * * *$ & $1.639 * * *$ & $1.747 * * *$ & $1.819 * * *$ \\
\hline Engine crew & & -.014 & -0.021 & .086 & .113 \\
\hline Victualling crew (ref) & & - & - & - & - \\
\hline English & & & -.153 & -.141 & \\
\hline USA & & & .019 & -.021 & \\
\hline Other (ref) & & & - & - & \\
\hline Single & & & -.044 & -.065 & \\
\hline With children & & & .215 & .199 & \\
\hline Age: $51+$ & & & $-.526 * *$ & -.352 & $-.500 * *$ \\
\hline Sex * child & & & & $-.839 * * *$ & $-1.541 * * *$ \\
\hline Age $51+* 1$. class & & & & -.078 & \\
\hline Age $51+* 2$. class & & & & -.449 & \\
\hline Age $51+* 3$. class & & & & -.958 & \\
\hline Sex $* 1$. class & & & & $-.690 *$ & -.257 \\
\hline Sex $* 2$. class & & & & .005 & \\
\hline Sex $* 3$. class & & & & $-.1 .173 * * *$ & $-1.130 * * *$ \\
\hline 1. Class $* 1$. phase & & & & & $3.797 * * *$ \\
\hline 1. Class $* 2$. phase & & & & & .488 \\
\hline Child $* 2$. phase & & & & & .934 \\
\hline Child $* 3$. phase & & & & & $1.597 *$ \\
\hline 1. class $*$ Sex $* 1$. phase & & & & & $-2.209 * * *$ \\
\hline 1. class $* \operatorname{Sex} * 2$. phase & & & & & .297 \\
\hline Chi square & 16.069 & 65.607 & 72.937 & 104.016 & 34.446 \\
\hline R-square ${ }^{a}$ & $18.9 \%$ & $28.4 \%$ & $28.9 \%$ & $30.3 \%$ & $35.5 \%$ \\
\hline Concordance & .668 & .752 & .756 & .773 & .789 \\
\hline
\end{tabular}

${ }^{\text {a }} \mathrm{R}$-square is calculated with $\mathrm{N}=2188$

game-mechanisms leading to the outcome, and then both recoding the quantitative variables and coding the testimonies with respect to these same game-mechanisms.

\section{Results}

\subsection{A survival analysis of accessing lifeboats}

The results of our survival analysis are presented in Table 2 in a series of consecutive models. Model 1 only enters gender and child (age $<15)$. Gender is highly significant; child is 
not (later models will show a significant interaction between child and gender). The model explains $18.9 \%$ of the variance. Model 2 adds the variable class/type of crew. This variable has a very strong and significant effect, increasing explained variance to $28.4 \%$. Model 3 adds the variables nationality (English, American, other), social ties (dummies for being single and traveling with children), and a dummy for being 51 or older. While the age variable is significant, neither nationality nor social ties explains anything, so that explained variance is increased only slightly (but significantly) to $28.9 \%$. Model 4 adds several twoway interactions and again permits us to increase explained variance slightly, but significantly, to $30.3 \%$. However, all models 1 to 4 have a poor fit. Further inspection reveals that the reason for this lies in the fact that the proportional hazard assumption is violated. In model 5, we therefore follow the suggestions of Therneau and Grambsch (2000), and partition the time axis. We choose the time points $55 \mathrm{~min}$ and $89 \mathrm{~min}$, creating three phases, permitting different causal structures for the different phases. We arrived at these two cutting points inductively with the help of a combination of our qualitative knowledge of the lifeboat-filling procedures and the results of a stepwise regression. In fact, phase 1 (1-55 $\mathrm{min}$ ) coincides with the filling of the first three lifeboats on the starboard side $(7,5$, 3 ); phase 2 (56-89 min), with the filling mainly of lifeboats on the aft port side $(6,16,14$, 12) and boat 1 on the starboard side; and the last phase, with the filling of the remaining lifeboats.

The final model (number 5) leaves out nationality and social ties (which proved insignificant in model 4), and adds the effect of different time phases in the form of interactions. The explained variance is $35.5 \%$ and concordance is $.789 .^{8}$

In essence, the model says that, controlling for all other variables included in the model,

- Women have a higher survival probability than men.

- Class/type of crew remains a very strong predictor, although its influence is mediated by gender and its influence changes over time. Third-class passengers and restaurant crew have a lower, and deck crew a higher, survival probability.

- Adults of 51 and older have a lower survival probability.

- Being a child increases the survival probability for males much more than for females; and children who travel as third-class passengers have a higher survival probability than adult third-class passengers in the third phase.

- Third-class female passengers have a significantly lower survival probability than other women.

- First-class passengers, especially men, have a significantly higher survival probability in the first phase.

This analysis gives rise to a number of more general points. First, that the general differences found in the trivariate presentation between gender, class, and survival remain significant in a multivariate perspective. Second, that we can falsify hypotheses 4 and 5 concerning "nationality" and "social ties", and can explain the dynamics according only to gender, class, and their interactions. Third, that different stages in the process must be distinguished, since they exhibit different causal structures.

\footnotetext{
${ }^{8}$ A test of proportionality shows that the global model still has a significant lack of fit, although none of the individual variables do. With the variables available, we were nonetheless unable to find a model that fits better.
} 

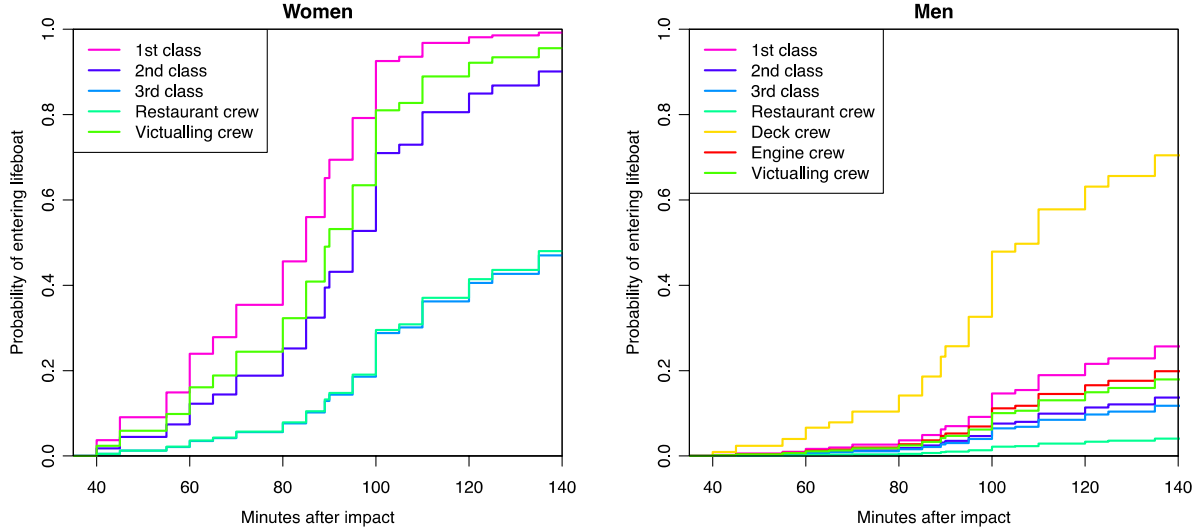

Fig. 2 Predicted marginal probabilities of boarding a lifeboat for men and women of different class/crew (model 6)

Table 3 Number of testimonies of people having experienced an attribute of a situation during the filling of the boat they survived in

\begin{tabular}{|c|c|c|c|c|c|c|c|c|c|c|c|c|c|c|c|c|c|c|c|c|}
\hline & \multicolumn{20}{|c|}{ Boats in order of leaving the Titanic } \\
\hline Number of lifeboat & 7 & 5 & 3 & 8 & 1 & 6 & 16 & 14 & 12 & 9 & 11 & 13 & 15 & 2 & 10 & 4 & $\mathrm{C}$ & $\mathrm{D}$ & $\mathrm{B}$ & A \\
\hline Port/Starboard & $\mathrm{S}$ & $\mathrm{S}$ & $\mathrm{S}$ & $\mathrm{P}$ & $\mathrm{S}$ & $\mathrm{P}$ & $\mathrm{P}$ & $\mathrm{P}$ & $\mathrm{P}$ & $\mathrm{S}$ & $\mathrm{S}$ & $\mathrm{S}$ & $\mathrm{S}$ & $\mathrm{P}$ & $\mathrm{P}$ & $\mathrm{P}$ & $\mathrm{S}$ & $\mathrm{P}$ & $\mathrm{P}$ & $\mathrm{S}$ \\
\hline \multirow[t]{2}{*}{ Launched } & $0: 40$ & $0: 45$ & $0: 55$ & 1:00 & $1: 05$ & $1: 10$ & $1: 20$ & $1: 25$ & $1: 30$ & $1: 30$ & $1: 35$ & $1: 40$ & $1: 40$ & $1: 45$ & $1: 50$ & $1: 50$ & 2:00 & $2: 05$ & $2: 15$ & $2: 15$ \\
\hline & & & & & & & & & & & & & & & & & & & & \\
\hline \multicolumn{21}{|l|}{ Filling rules } \\
\hline Women/children first & 3 & 9 & 4 & 8 & 2 & 8 & 6 & 8 & 7 & 6 & 8 & 10 & 4 & 8 & 9 & 8 & 7 & 4 & 0 & 0 \\
\hline Fill up with men & 2 & 7 & 4 & 0 & 0 & 0 & \begin{tabular}{|l|}
0 \\
\end{tabular} & \begin{tabular}{|l}
0 \\
\end{tabular} & 4 & 1 & 5 & 4 & 0 & 1 & 1 & 2 & \begin{tabular}{|l|}
0 \\
\end{tabular} & 0 & 0 & 0 \\
\hline Couples first & 2 & 1 & 0 & 0 & 0 & 0 & 0 & 0 & 0 & 0 & 0 & 0 & 0 & 0 & 0 & 0 & 0 & 0 & 0 & 0 \\
\hline Anybody & 4 & 2 & 0 & \begin{tabular}{|l|}
0 \\
\end{tabular} & 5 & 0 & 0 & 0 & 0 & 0 & 0 & 0 & \begin{tabular}{|l|}
0 \\
\end{tabular} & \begin{tabular}{|l|}
0 \\
\end{tabular} & \begin{tabular}{|l|}
0 \\
\end{tabular} & 0 & 0 & 0 & 9 & 3 \\
\hline & & & & & & & & & & & & & & & & & & & & \\
\hline \multicolumn{21}{|l|}{ Filling context } \\
\hline Shortage of women & 2 & 2 & 3 & 1 & 2 & 2 & 1 & 0 & 0 & 4 & 1 & 5 & 4 & 1 & 2 & 0 & 2 & 1 & 0 & 0 \\
\hline Women hesitate & 2 & 2 & 0 & 3 & 0 & 3 & 1 & 0 & 0 & 2 & 3 & 1 & 0 & 0 & 1 & 1 & 0 & 1 & 1 & 1 \\
\hline & & & & & & & & & & & & & & & & & & & & \\
\hline \multicolumn{21}{|l|}{ Authority \& limits } \\
\hline Officers in charge & 7 & 10 & 3 & 6 & 8 & 5 & 3 & 9 & 3 & 5 & 3 & 6 & 3 & 5 & 5 & 2 & 2 & 0 & 0 & 0 \\
\hline People calm, orderly & 4 & 5 & 1 & 4 & 2 & 2 & 2 & 0 & 0 & 2 & 4 & 7 & 1 & 4 & 3 & 2 & 1 & 1 & 0 & 0 \\
\hline People agitated & 0 & 0 & 1 & 0 & 0 & 2 & 1 & 5 & 2 & 0 & 0 & 6 & 2 & 0 & 1 & 0 & 2 & 0 & 2 & 0 \\
\hline Men try to sneak in & 0 & 1 & \begin{tabular}{|l|}
0 \\
\end{tabular} & 0 & 0 & 5 & 0 & 1 & 3 & 0 & 3 & 5 & 1 & 4 & 5 & 2 & 2 & 2 & 0 & 0 \\
\hline Men try to rush boats & 0 & 0 & 0 & 0 & 0 & 0 & 0 & 6 & 1 & 0 & 0 & 1 & 1 & 0 & 0 & 0 & 0 & 0 & 0 & 0 \\
\hline Officers establish order & 0 & 0 & 0 & 0 & 0 & 1 & 0 & 7 & 2 & 0 & 0 & 4 & 0 & 3 & 2 & 0 & 2 & 0 & 1 & 0 \\
\hline Total & 26 & \begin{tabular}{|l}
39 \\
\end{tabular} & \begin{tabular}{|l}
16 \\
\end{tabular} & 22 & 20 & 28 & \begin{tabular}{|l}
12 \\
\end{tabular} & 36 & \begin{tabular}{|l}
18 \\
\end{tabular} & 23 & 23 & 51 & 20 & 25 & 29 & 15 & 20 & \begin{tabular}{|l}
8 \\
\end{tabular} & 14 & 4 \\
\hline N (Documents) & \begin{tabular}{|l|}
11 \\
11
\end{tabular} & \begin{tabular}{|l|}
16 \\
\end{tabular} & \begin{tabular}{|l}
6 \\
6
\end{tabular} & \begin{tabular}{|l|}
22 \\
9
\end{tabular} & \begin{tabular}{|l|}
10 \\
10
\end{tabular} & \begin{tabular}{|l|}
8 \\
\end{tabular} & \begin{tabular}{|l|}
10 \\
\end{tabular} & \begin{tabular}{|l|}
15 \\
\end{tabular} & \begin{tabular}{|l|}
9 \\
\end{tabular} & 8 & \begin{tabular}{|l|}
25 \\
14
\end{tabular} & \begin{tabular}{|l|}
1 \\
18
\end{tabular} & \begin{tabular}{|l|}
20 \\
9
\end{tabular} & \begin{tabular}{|l|}
5 \\
10
\end{tabular} & \begin{tabular}{|l|}
5 \\
10
\end{tabular} & \begin{tabular}{|l|}
15 \\
15 \\
\end{tabular} & \begin{tabular}{|l}
20 \\
9
\end{tabular} & \begin{tabular}{|l}
6 \\
\end{tabular} & \begin{tabular}{|l|}
17 \\
\end{tabular} & \begin{tabular}{|l|}
5 \\
\end{tabular} \\
\hline
\end{tabular}

Cells with higher numbers have darker grey for better visual inspection

Figure 2 shows the predicted marginal probabilities of accessing a lifeboat for men and women, and for different class/type of crew, over time.

\subsection{A content analysis of testimonies}

The content analysis complements and specifies the insights from the survival analysis in important ways. Since survivors experienced and observed the actual "game-in-action", their testimonies can help us decide what exact game-mechanisms were at work. We focus on lifeboat-filling rules, authority of officers and crew, information procedures, and passengers' route to the boat deck. 

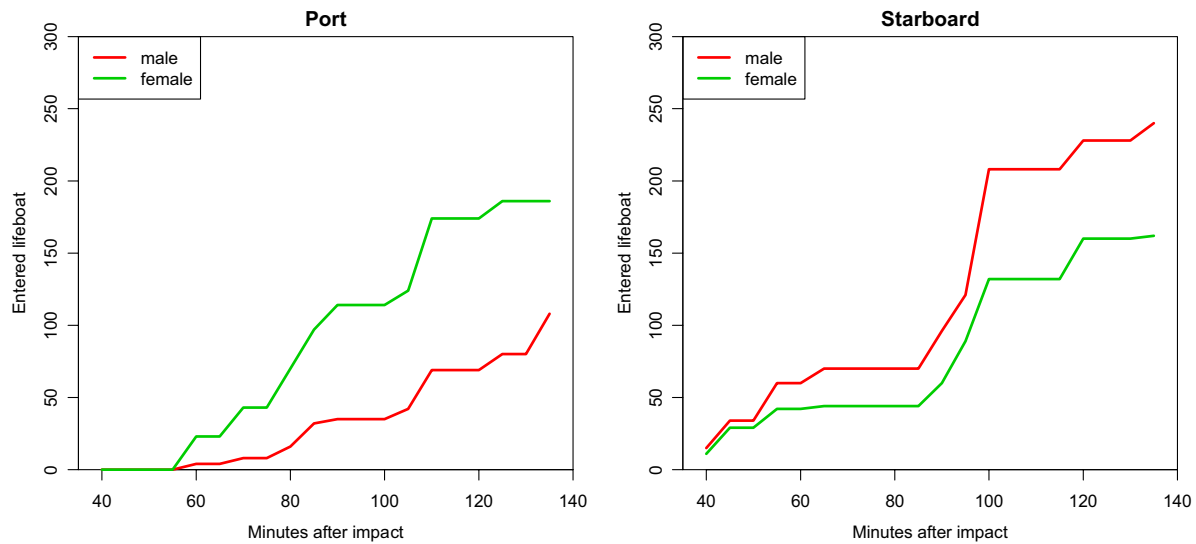

Fig. 3 Women and men boarding lifeboats on port and starboard side according to time after impact

\subsection{Lifeboat-filling rules, their context and application}

Table 3 provides systematic information on the testimonies that survivors gave about the lifeboat-filling rules applied, and the contexts in which the lifeboats were filled.

The first point is that the "women-and-children-first" rule was indeed applied in all but the last two lifeboats. ${ }^{9}$ This rule is the one manifest rule that was consciously applied, and it influenced the process as a whole (it was actually given as an order by Captain Smith). However, passengers, especially in the first two boats, were under the impression that other rules were also applied, such as "couples first", or "anybody" (see "lifeboat-filling rules" in Table 3).

Second, officers wanted to apply the rule "women and children first", but were not always able to do so, either because there were not enough women on deck at that moment or because the women who were on deck hesitated or refused to board a lifeboat (see the row "lifeboat-filling context" in Table 3).

Third, the officers in charge on the port side and the starboard side reacted differently to the shortage of women by interpreting the rule "women and children first" in different ways. On the port side, boats were lowered usually without allowing additional men into the boats; on the starboard side, however, the boats were normally "filled up with men and crew". This fact is clearly visible from Table 3 (rows "port/starboard" and "fill up with men"). According to survivor accounts, it was officer Lightoller on the port side and officer Murdoch on the starboard side who interpreted the general rule differently.

The following coded segments (all from lifeboats on the starboard side) give an impression of how the "filling-up-with-men" mechanism worked:

- and two other women entered one of the first boats lowered. Twelve men, including myself, were standing near. As there were no other women passengers waiting to get

\footnotetext{
9 The last two boats were washed off the Titanic. It is also an open question whether the rule was applied for boat 1 , which was lowered by officer Lightoller with only a handful of people on it.
} 
into the boats at that time, we were asked to accompany the women (Frolicher, Max, Boat 5).

- There were no more women to go and I asked the officer if there was any objection to my going in that boat. He said, "No, get in" and I was the last one in. I think it was the third from the last to go on that side. It was No. 9 (Collett Sidney Stuart, Boat 9).

- I assisted six, three women and three children. The order was then given to lower the boat. The chief officer wanted to know if there were more women and children. There were none in the vicinity. Two gentlemen passengers got in; the boat was then lowered (Rowe, George, Collapsible C).

The fact that the rule was interpreted differently on the port side and the starboard side had a striking effect (Fig. 3): while many more women boarded a lifeboat than men on the port side, men eventually outnumbered women in the lifeboats on the starboard side.

Fourth, the rule "women and children first" was evidently less strongly applied at both the beginning and the end of the process. At the beginning, in the first two boats, passengers appear to have been very reluctant to board a lifeboat, since they seemed unsafe (less safe than the apparently unsinkable Titanic in any case) and very high up. This also seems to have been the reason why the officers were more willing to allow men into the lifeboats. By the end of the lifeboat-filling process, the water had already reached the deck and an orderly process was no longer possible. This is the reason that the last two boats were filled with anybody who could hang onto them.

\subsection{Authority and its limits}

Why and how did men accept the rule "women and children first", even though they themselves could perish as a result of it? Again, the survival analysis leaves us guessing, while triangulating it with the results from the content analysis helps us flesh out the game-mechanism. We can compare in the second part of Table 3 how authority was exercised and accepted across boats and time. We can see that all but the last three boats were filled by an officer who was clearly in charge: he oversaw the filling process, ordering individuals into the boats or preventing them from boarding (Table 3, "officers in charge"). This authority exercised by the officers was generally very well accepted and the process of filling the lifeboats is described in most cases as calm (Table 3, "people calm, orderly"):

- An officer there shouted, "All men back, women come first". There was no attempt of any of the men to get into the boat (Howard, May Elisabeth, Collapsible C)

- Did they try to get in or was it orderly?-Quite orderly. Everyone obeyed orders. Everything was quite calm (Beauchamp, George, Boat 13).

- Did they crowd round the boats at all?-No; they all kept good order; they kept back to give the men working room. Was there an order?-Yes, there was one order when we were at boat No. 3. Two or three men of some description, whether stewards or passengers I do not know, were asked to keep back to give the men room to work (Symonds, George, Boat 1).

We also note that this was not always the case. At some points, and especially after 1:10 am, some people began to become agitated and there were attempts to rush boats 12 and 14. Also, several men tried to sneak or jump into the boats against the order of the officers. This is why we see the officers acting in an authoritarian manner, sometimes even 
Table 4 Number of testimonies of people having experienced an attribute of a situation during their way to the boat deck; reconstructed arrival time

\begin{tabular}{|l|l|l|l|l|l|l|c|}
\hline & Class 1 & Class 2 & Class 3 & $\begin{array}{l}\text { Deck } \\
\text { crew }\end{array}$ & $\begin{array}{l}\text { Restau- } \\
\text { rant } \\
\text { crew }\end{array}$ & $\begin{array}{l}\text { Engine } \\
\text { crew }\end{array}$ & $\begin{array}{l}\text { Victual- } \\
\text { ling } \\
\text { crew }\end{array}$ \\
\hline Way to boat deck & & & & & & & \\
\hline $\begin{array}{l}\text { On first decks at } \\
\text { impact }\end{array}$ & 8 & 0 & 0 & 3 & & & \\
\hline Informed by crew & 13 & 7 & 3 & 12 & & 1 & 15 \\
\hline On other decks first & 1 & 1 & 5 & 5 & & 3 & \\
\hline $\begin{array}{l}\text { Difficult way to boat } \\
\text { deck }\end{array}$ & 0 & 4 & 6 & & 1 & 3 & \\
\hline $\begin{array}{l}\text { Crowd obstructs } \\
\text { passage }\end{array}$ & 0 & 1 & 4 & & & & \\
\hline $\begin{array}{l}\text { Crew obstructs / } \\
\text { unhelpful }\end{array}$ & 0 & 1 & 7 & & 1 & & \\
\hline Finds gates locked & 0 & 0 & 3 & & & & \\
\hline Finds gates open & 0 & 0 & 3 & & & & \\
\hline & & & & & & & \\
\hline $\begin{array}{l}\text { Arrival time on boat } \\
\text { deck }\end{array}$ & & & & & & & \\
\hline$<00: 40$ & 32 & 3 & 2 & 24 & & 1 & 5 \\
\hline $00: 41-1: 20$ & 16 & 4 & 4 & & & & 8 \\
\hline $1: 21-02: 05$ & 5 & 15 & 19 & & 1 & 6 & 7 \\
\hline$>02: 05$ & & & 3 & & & 3 & 1 \\
\hline & 53 & 22 & 28 & 24 & 1 & 10 & 21 \\
\hline Total & 69 & 34 & 36 & 28 & 2 & 17 & 29 \\
\hline N (Documents) & & & & & & \\
\hline
\end{tabular}

Cells with higher numbers have darker grey for better visual inspection

threatening to shoot men who would not obey orders (there seem to have been three actual shootings in all). ${ }^{10}$ Especially third-class passengers and crew seem to have tried to sneak into and rush the lifeboats.

\subsection{Information and the route to the boat deck}

What mechanism was in operation to increase the survival probability among the higherclass passengers? Table 4 gives systematic information on distance to and arrival time at the boat deck for different classes and crew types. There are (more or less) no indications that conscious class discrimination played a role when filling the lifeboats or informing the passengers. However, structural conditions did favor the higher classes significantly.

- A first point concerns information. No general alarm was given on the Titanic to inform the passengers. Instead, the stewards were ordered to inform "their" passengers. Since there were more stewards to cater to the first-class passengers than to

10 https://www.encyclopedia-titanica.org/gunshots-on-titanic.html. 
the second-class and third-class passengers, ${ }^{11}$ and since the distance from the point at which the stewards were given their order was less to the first-class cabins, those passengers belonging to the higher classes were informed earlier and better, were more convinced of the dangers that they faced, and were given more help. Furthermore, the higher-class passengers also had access to the boat deck under normal conditions, which was not the case for the third-class passengers. As a consequence, they knew where the boat deck and the lifeboats were, while the third-class passengers did not.

- A second point concerns the length and difficulty of the route to the boat deck (Table 4). Second-class (and especially third-class) passengers were more likely to go to other decks than the boat deck (thus losing time); they more often described their route to the boat deck as being difficult, crowded, or obstructed by crew; and some say that the gates to the boat deck were locked. While there is conflicting evidence concerning the locked gates, the overall impression is that it was much more difficult for second-class and especially for third-class passengers to reach the boat deck in time than it was for first-class passengers (Table 4). To give just one example of how difficult the route to the boat deck could be for a third-class passenger, we can consider the testimony of Yarred Elias Nicola, an eleven-year-old boy with a third-class ticket:

We had steerage-class tickets, meaning we could go up to the second-class deck. But those on second-class and steerage could not pass through a guarded gate that led to the first-class upper deck. However, we were told it would be wise to get to the firstclass upper deck in order to have a better chance of getting into a lifeboat. The only way this could be done was to climb an iron ladder from the steerage deck below up five or six decks to the lifeboats above. This we did with much difficulty, (...) (Yarred Elias Nicola, third-class child passenger).

These points combined had the effect that it was almost exclusively first-class passengers who were on the boat deck during the first $55 \mathrm{~min}$, the period when the first lifeboats were launched. It also had the effect that first-class passengers were on the boat deck earlier than second-class passengers, and they in turn earlier than third-class passengers (who in fact often never even reached the boat deck until after the last lifeboat had left) (Table 4, arrival time on boat deck).

How reliable are the results of our content analysis? We can say that the results concerning the rules governing the filling of lifeboats and the authority relations while filling them are very reliable. This is because the information concerning the filling of specific lifeboats can be cross-checked from accounts provided by other survivors in the same lifeboat. The results alone of our content analysis concerning the route to the boat deck are somewhat less reliable, since the route to the boat deck might vary considerably from one individual to the next, and cross-checking is more difficult. Nonetheless, our overall impression fits our general, and very reliable, context knowledge very well: namely, that second-class and third-class cabins were much further from the boat deck, that third-class passenger normally did not have access to the boat deck area, and that they were informed of what was happening by the crew much later.

Combining the survival and content analysis allows us to solve some additional riddles that would otherwise remain obscure.

\footnotetext{
${ }^{11}$ The ratio of bedroom stewards to passengers was $10.8 \%$ (1st class), $4.2 \%$ (2nd class), and $6.2 \%$ (3rd class).
} 
- Why did the officers not fill the lifeboats to capacity? They were in fact convinced that the lifeboats might break or capsize if filled to capacity in the air. Doing so would have meant taking a great risk, especially during the early phase of filling the lifeboats, when the officers still thought that the Titanic would remain afloat.

- Why was it that not all first-class female passengers survived? Some first-class female passengers refused to board a lifeboat, either because they had no confidence in the small boats, or because they did not want to leave their husbands.

- Why did second-class male passengers not have a higher survival probability than third-class male passengers? This can be explained by the fact that, when second-class male passengers reached the boat deck (in our "second phase"), only a small number of lifeboats were lowered on the port side, which saw a very strict "women-and-children-only" rule being applied. Thus, the "window of opportunity" remained closed for second-class male passengers.

- Why did so many of the restaurant crew drown? This can be explained if we believe the testimony provided by one survivor from the restaurant crew, Paul Mauge, who recounts that the men from the restaurant crew were held back under deck by stewards. Mauge himself, according to his testimony, managed to elude the stewards by tricking them.

- Why did male deck crew have such a high survival probability? This is easily explained by the fact that every lifeboat had to have a male member of the crew who would be in charge and row. A male member of the deck crew was assigned by officers to each lifeboat.

Not all riddles can be easily solved by using mixed methods. Why, for example, did officer Lightoller lower boat 1 with only five people on board? Yet, we can give a satisfactory explanation for the large variations in survival probabilities through the mechanisms presented here.

\section{Conclusion}

The goal of this paper has been to introduce an example of a mixed-method explanation, using the well-known case of the Titanic. We have argued that this example, which is often used to teach statistical methods, can actually be better explained when using mixed methods. A mixed-method explanation is superior to a mono-method explanation in that it clarifies not only the relationships between variables, but also the mechanisms that led to the co-variations. We not only predict different survival rates for different groups, but also show why these different rates come about.

Our results are both substantive and methodological. Substantively, we were able to test our hypotheses in a robust way by combining the results of a survival analysis and a content analysis. Very briefly, our analysis suggests that the differences in survival probability are a result of three interrelated features of the "social game": different classes arriving at different times on the boat deck; a gender rule applied differently on port side and starboard side; and the context factor that there were not enough lifeboats. To provide more detail: women and children survived more often than men because of the rule "women and children first", which was the one rule that officers and crew consciously applied throughout the process. Whenever a woman or a child was in sight, that passenger was allowed into the lifeboat first. However, the rule was interpreted differently on the starboard side (where the 
lifeboats were "filled up with men", once no more women or children were in sight) to how it was interpreted on the port side (where only women and children, and the necessary male crew member, were allowed to board a lifeboat). Higher-class female passengers survived more often than lower-class female passengers, because they were earlier to reach the boat deck. Men could survive for reasons that changed over time. In the first phase, first-class male passengers could board lifeboats, since they were the only men on the boat deck and first-class female passengers were rather reluctant to board a lifeboat. In the second phase, a number of lifeboats were lowered on the port side, which had a very strict "women-andchildren-only" rule, meaning that men (except those belonging to the deck crew) had a very small chance of boarding a lifeboat. The tragedy of second-class male passengers is that they had reached the boat deck by this time, but were not allowed to board these boats. In the third phase, crew and third-class male passengers seem to have been both more numerous and enterprising when "filling up" and "sneaking onto" the boats, thus crowding out both first-class and second-class male passengers. Once in the water, younger men had an advantage over older men when it came to being picked up by a lifeboat (which only rarely happened; and only one woman survived in this way). Discrimination against lower-class passengers was not a conscious policy when filling the boats; rather, it was a combination of several mechanisms, including the fact that cabins occupied by the lower classes were much further away from the boat deck, that access to the boat deck was normally denied to third-class passengers, and that fewer stewards attended to them. It is important to note that we do not need mechanisms linked to nationality or social ties to explain the findings.

Former research has already shown the massive gender and class differences in survival (Frey et al. 2011; Hall 1986; Gleicher and Stevans 2004). Gleicher and Stevans (2004) already show the basic effects and interactions of sex and gender and interpret them as resulting from filling policy and differential access to the boat deck. They also note the different interpretation of filling rules on Starboard and Port. However, their analysis lacks a clear mixed methods methodology that uses systematic data linking, and analysis procedures for both types of data. What our research adds substantively to this state of the art is : (1) a better description of the explanandum by distinguishing different types of crew and explaining their differential survival probability; (2) a more thorough quantitative analysis that incorporates the temporal sequence of events, showing that the parameter estimates change over time; (3) a demonstration (and not just conjecture) of how the way-to-theboat-deck and filling rules mechanisms differed for different classes and differently on Starboard/Port.

But our example also provides several important methodological insights that may be applied to explanatory mixed methods in general:

1. In our example, the fine-grained description gleaned from the qualitative material led to a more realistic specification and analysis of the quantitative model. Thus, it inspired us to use "time of boarding a lifeboat" as our dependent variable and to distinguish lifeboat-filling practices on the port side from those on the starboard side.

2. Conversely, our quantitative analysis also led to a more realistic interpretation of the qualitative material. Had we only performed the qualitative content analysis, we might have exaggerated or overgeneralized salient elements in the qualitative data. For example, the fact that some first-class female passengers chose to stay on board and then died with their husbands occupies a lot of space in the survivor accounts. But quantitative analysis shows that, although interesting, this phenomenon must have been rare, since $96.5 \%$ of the first-class female passengers survived. 
3. Our example shows that, instead of simply hypothesizing basic assumptions about the process (as was the case in the mono-method treatment of the Titanic), such assumptions can be produced through a careful triangulation of quantitative and qualitative material. For example, in the article by Frey et al. (2011), it is hypothesized in an abstract way that the rule "women and children first" plays an important role, and readers are left with the impression that individuals somehow just followed that rule. What is omitted in this account is that this rule was formulated, interpreted, and enforced by the officers, and that it was only effective because they succeeded in maintaining their authority on board.

4. Our example has shown that the "cogs and wheels" of the game-mechanism are nothing more than the interrelated game-elements in action. It is the actions, rules, resources, etc. that work together in a typical way as the game unfolds and thus transform the effect of "explanatory variables" into "outcomes". For example, the attribute of "being a woman" only leads to a higher probability of survival, because the officers apply the rule "women and children first". However, this only helps those women who have the necessary resources (information, knowledge, and access) that allow them to reach the boat deck earlier than others.

5. Another point is that the game-elements are thoroughly symbolic. Rules, resources, player-attributes, and objects have to be interpreted in order to be usable in the game. Thus, individuals knew the rule "women and children first" in the abstract, but the rule nevertheless had to be interpreted (and was interpreted quite differently) in the specific situations. To take another example: the player-attribute "being a man" involved honour, with first-class male passengers in particular facing the question of whether it was appropriate to board a lifeboat when there were still women on the ship, and how they could do so without being seen as a coward; one solution open to such a passenger was to reinterpret the issue by pretending to board the lifeboat in order to "take care" of his wife (or other ladies).

6. Our explanation gives more importance to time, space, and context than do monomethod explanations. We need only consider that our explanation rests on the fact that different classes reached the boat deck at different points in time, and that this was due among other things to the spatial arrangements of the ship, and to the fact that the loss of life was so high because the number of lifeboats legally prescribed was not sufficient for the number of passengers on board (which is related to the legal context).

7. Finally, our example shows the causal nature of our mixed-method explanation. Playing the Titanic-game again, with the same game-parameters (e.g. the same number of lifeboats, classes arriving at different times, and a different interpretation of the rule "women and children first" on the port side and the starboard side), would lead us to very similar survival rates. However, if we changed one or several of the game-parameters (say, abolished the rule "women and children first", or increased the number of lifeboats), then the outcome would change significantly.

Readers might ask whether the methodology used in this paper can be applied to other cases. After all, it is rather unusual to have naturally occurring data in which hundreds of individuals all testify on the same event. The mixed-method literature shows, however, that it is easy to design linked qualitative and quantitative datasets to the same effect (Creswell and Plano Clark 2010). Admittedly, in this paper we have only been able to hint at the usefulness of the theory of social games and game heuristics for mixed methods research. Future publications will have to explain this further. 
To conclude, we reiterate that we are not arguing against using the Titanic data to teach students statistical techniques such as log-linear models or logistic regression. We are saying, however, that such examples are of only limited value when it comes to explaining the Titanic findings sociologically. We have introduced the Titanic example to give a highly visible example of how statistical explanation may be turned into sociological explanation, thus showing how situated actions and interactions in a social game lead to the outcomes. We hope that the case of the Titanic may become an example of how to teach not only statistical methods but also sociological explanation.

Acknowledgements This work was done without additional third-party funding.

OpenAccess This article is distributed under the terms of the Creative Commons Attribution 4.0 International License (http://creativecommons.org/licenses/by/4.0/), which permits unrestricted use, distribution, and reproduction in any medium, provided you give appropriate credit to the original author(s) and the source, provide a link to the Creative Commons license, and indicate if changes were made.

\section{References}

Abbott, A.: From causes to events. In: Abbott, A. (ed.) Time Matters on Theory and Method, pp. 183-208. The University of Chicago Press, Chicago (2001)

Bellocco, R., Algeri, S.: Goodness-of-fit tests for categorical data. Stata J. 13(2), 356-365 (2013)

Bergman, M.M.E.: Advances in Mixed Methods Research. Sage, Los Angeles (2008)

Blumer, H. (ed.): Sociological analysis and the "variable" symbolic interactionism. In: Perspective and Method, pp. 127-139. University of California Press, Berkeley (1998/1969)

Boudon, R.: Which rational action theory for the forthcoming mainstream sociology: methodological individualism or rational choice? Eur. Soc. Rev. 17(4), 451-457 (2001)

Bourdieu, P.: Le sens pratique. Minuit, Paris (1980)

Bryman, A.: Why do researchers Integrate/Combine/Mesh/Blend/Mix/Merge/Fuse quantitative and qualitative research? In: Bergman, M.M.E. (ed.) Advances in Mixed Methods Research. Theories and Applications, pp. 87-100. SAGE, Los Angeles (2008)

Coleman, J.S.: Foundations of Social Theory. The Belknap Press of Harvard University Press, Cambridge (1990)

Creswell, J.W., Plano Clark, V.L.: Designing and Conducting Mixed Methods Research, 2nd edn. Sage, Thousand Oaks (2010)

Eaton, J.P., Haas, C.: Titanic Triumph and Tragedy, 3rd edn. Haynes, London (2011)

Esser, H.: What is wrong with "variable sociology"? Eur. Soc. Rev. 12(2), 159-166 (1996)

Fox, J., Weisberg, S.: Cox Proportional-Hazards Regression for Survival Data in R. An Appendix to an R Companion to Applied Regression, 2nd edn. https://socserv.socsci.mcmaster.ca/jfox/Books/Compa nion/appendix/Appendix-Cox-Regression.pdf (2011). Accessed 12 Nov 2017

Frey, B.S., Savage, D.A., Torgler, B.: Who perished on the Titanic? The importance of social norms. Ration. Soc. 23(1), 35-49 (2011)

Gleicher, D., Stevans, L.K.: Who survived the Titanic? A logistic regression analysis. Int. Rev. Marit. Hist. 16(2), 61-94 (2004)

Gross, N.: A pragmatist theory of social mechanisms. Am. Soc. Rev. 74(June), 358-379 (2009)

Hall, W.: Social class and survival on the S.S.Titanic. Soc. Sci. Med. 22(6), 687-690 (1986)

Harrell, F.: Regression Modeling Strategies. With Applications to Linear Models, Logistic Regression, and Survival Analysis. Springer, Berlin (2001)

Hedström, P.: Dissecting the Social. On the Principles of Analytical Sociology. Cambridge University Press, Cambridge (2005)

Howe, K.R.: Mixed methods, triangulation, and causal explanation. J. Mix. Methods Res. 6(2), 89-96 (2012)

Ivankova, N.V., Creswell, J.W., Stick, S.L.: Using mixed-methods sequential explanatory design: from theory to practice. Field Methods 18(1), 3-20 (2006) 
Johnson, B., Turner, L.A.: Data collection strategies in mixed methods research. In: Tashakkori, A., Teddlie, C. (eds.) Handbook of Mixed Methods in Social and Behavioural Research, pp. 297-320. Sage, Thousand Oaks (2003)

Johnson, R.B., Onwuegbuzie, A.J.: Mixed methods research: a research paradigm whose time has come. Educ. Res. 33(7), 14-26 (2004)

Kelle, U.: Sociological explanations between micro and macro and the integration of qualitative and quantitative methods [43 paragraphs]. Forum: Qual. Soc. Res. [On-line Journal]. http://qualitative-research. net/fqs/fqs-eng.htm. Date of Access: 10 Apr 2008, 2(1) (2001)

King, G., Keohane, R.O., Verba, S.: Designing Social Inquiry. Scientific Inference in Qualitative Research. Princeton University Press, Princeton (1994)

Klabbers, J.H.G.: The gaming landscape: a taxonomy for classifying games and simulations. In: Copier, M., Raessens, J. (eds.) Level Up: Digital Games Research Conference, pp. 54-68. University of Utrecht, Utrecht (2003)

Kohler, U., Kreuter, F.: Datenanalyse mit Stata. Allgemeine Konzepte der Datenanalyse und ihre praktische Anwendung. 5. Auflage. Oldenbourg: De Gruyter (2017)

Landau, S., Everitt, B.S.: Chapter 9: Logistic Regression: Who Survived the Sinking of the Titanic? A Handbook of Statistical Analyses using SPSS. Chapman \& Hall/CRC, London (2004)

Lieberman, E.S.: Nested analysis as a mixed-method strategy for comparative research. Am. Politi. Sci. Rev. 99(3), 435-452 (2005)

Little, D.: Analytical sociology and the rest of sociology. Sociologica (2012). https://doi.org/10.2383/36894

Lord, W.A.: Night to Remember. Penguin, London (2012/1956)

Manzo, G.: Analytical sociology and its critics. Eur. J. Soc. 51(1), 129-170 (2010)

Mayring, P.: Qualitative Content Analysis. Theoretical Foundation and Basic Procedures. http://www.quali tative-content-analysis.aau.at/ (2014)

Stachura, Mateusz: Bewertungsspiele. Von Der Handlungs- Zur Koordinationstheorie. Kölner Zeitschrift für Soziologie und Sozialpsychologie 69, 1-26 (2017)

Stolz, J.: Opening the Black Box. How the Study of Social Mechanisms can benefit from the Use of Explanatory Mixed Methods. Analyse und Kritik. 37(1), 257-285 (2016)

Swedberg, Richard: Sociology and game theory: contemporary and historical perspectives. Theory Soc. 30(3), 301-335 (2001)

Teddlie, C., Tashakkori, A.: Foundations of Mixed Methods Research. Integrating Quantitative and Qualitative Approaches in the Social and Behavioral Sciences. Sage, Los Angeles (2009)

Therneau, T.M., Grambsch, P.M.: Modeling Survival Data. Extending the Cox Model. Springer, New York (2000)

Thomas, L., Reyes, E.M.: Tutorial: Survival Estimation for Cox Regression Models with Time-Varying Coefficients Using SAS and R. J. Stat. Softw. 61(1), 1-23 (2014)

von Neumann, J., Morgenstern, O.: Theory of Games and Economic Behaviour. Princeton University Press, Princeton (2004/1944)

Publisher's Note Springer Nature remains neutral with regard to jurisdictional claims in published maps and institutional affiliations. 